\title{
Octreotide promotes apoptosis in human somatotroph tumor cells by activating somatostatin receptor type 2
}

\author{
E Ferrante, C Pellegrini ${ }^{1}$, S Bondioni, E Peverelli, M Locatelli ${ }^{2}$, Gelmini ${ }^{3}$, \\ $P$ Luciani $^{3}$, A Peri', G Mantovani, S Bosari ${ }^{3}, P$ Beck-Peccoz, A Spada and \\ A Lania
}

\begin{abstract}
Institute of Endocrine Sciences, University of Milan, Fondazione IRCCS, Ospedale Maggiore Policlinico, Mangiagalli, Regina Elena, Via Francesco Sforza 35, 20122 Milan, Italy

${ }^{1}$ Pathology Unit, Department of Medicine, Surgery and Dentistry, A O San Paolo, Milan, Italy

${ }^{2}$ Department of Neurosurgery, University of Milan, Fondazione IRCCS Ospedale Maggiore Policlinico, Mangiagalli, Regina Elena, Milan, Italy

${ }^{3}$ Endocrine Unit (AP) and Clinical Biochemistry Unit (GM), Department of Clinical Physiopathology, Center for Research, Transfer and High Education on Chronic, Inflammatory, Degenerative and Neoplastic Disorders for the Development of Novel Therapies (DENOThe), University of Florence, Florence, Italy
\end{abstract}

(Requests for offprints should be addressed to A Spada; Email: anna.spada@ unimi.it)

\begin{abstract}
Somatostatin analogs currently used in the treatment of acromegaly and other neuroendocrine tumors inhibit hormone secretion and cell proliferation by binding to somatostatin receptor type (SST) 2 and 5. The antiproliferative pathways coupled to these receptors have been only partially characterized. The aim of this study was to evaluate the effect of octreotide and super selective SST2 (BIM23120) and SST5 (BIM23206) analogs on apoptotic activity and apoptotic gene expression in human somatotroph tumor cells. Eight somatotroph tumors expressing similar levels of SST2 and SST5 evaluated by real-time PCR and western blot analyses were included in the study. In cultured cells obtained from these tumors, octreotide induced a dose-dependent increase of caspase-3 activity ( $160 \pm 20 \%$ vs basal at $10 \mathrm{nM}$ ) and cleaved cytokeratin 18 levels ( $172 \pm 25 \%$ vs basal) at concentrations higher than $0.1 \mathrm{nM}$. This effect was due to SST2 activation since BIM23120 elicited comparable responses, while BIM23206 was ineffective. BIM23120-stimulated apoptosis was dependent on phosphatases, since it was abrogated by the inhibitor orthovanadate, and independent from the induction of apoptosis-related genes, such as p53, p63, p73, Bcl-2, Bax, BID, BIK, TNFSF8, and FADD. In somatotroph tumors, both BIM23120 and BIM2306 caused growth arrest as indicated by the increase in p27 and decrease in cyclin D1 expression. In conclusion, the present study showed that octreotide-induced apoptosis in human somatotroph tumor cells by activating SST2. This effect, together with the cytostatic action exerted by both SST2 and SST5 analogs, might account for the tumor shrinkage observed in acromegalic patients treated with long-acting somatostatin analogs.
\end{abstract}

Endocrine-Related Cancer (2006) 13 955-962

\section{Introduction}

Somatostatin is a widely distributed polypeptide that predominantly exerts inhibitory effects on hormone secretion and cell proliferation by interacting with five different subtypes of receptors, named somatostatin receptor type (SST) 1 through 5. The binding of somatostatin to the receptor activates a number of $\mathrm{G}$ protein-linked transduction pathways, including adenylyl cyclase, calcium channels, phosphotyrosine phosphatase, and mitogen-activated protein kinase, largely depending on the SST subtype and the cell system considered (Hofland et al. 1999, Benali et al. 2000). Due to the physiological actions of somatostatin, long acting analogs that bind with high affinity SST2 and, to a less extent, SST5, such as octreotide and lanreotide, have been developed for the medical treatment of neuroendocrine tumors, in particular acromegaly (Hofland et al. 1999, Patel 1999, Lamberts 
et al. 2002, Weckbecker et al. 2003, Oberg et al. 2004, Bevan 2005, Freda et al. 2005).

The mechanisms mediating the antiproliferative action of somatostatin and the receptor subtypes involved in this process have been only partially characterized. In particular, studies on cell lines expressing SST1, SST2, SST4, and SST5 showed that somatostatin caused cell cycle arrest by inducing retinoblastoma tumor suppressor protein $(\mathrm{Rb})$ and cyclin-dependent kinase inhibitors, such as p27, p21, and p16 (Srikant 1995, Pages et al. 1999, Sharma et al. 1999). In contrast, until recently, SST3 was considered the receptor subtype mainly involved in the induction of cell death, although in some cell systems SST2 was shown to trigger both cytostatic and cytotoxic responses (Srikant 1995, Sharma et al. 1996, Gruszka et al. 2001). Consistent with these data, we recently reported the ability of octreotide to induce apoptosis in human somatotroph tumors, this response being associated with a reduced expression of seladin-1, a putative antiapoptotic gene (Luciani et al. 2005).

The aim of this study was to identify the receptor subtype involved in the proapoptotic action of octreotide by evaluating the effect of superselective somatostatin analogs on caspase activity and apoptosis-related gene expression in human somatotroph tumors.

\section{Materials and methods}

\section{Pituitary tissue samples and cell cultures}

The study included somatotroph tumors surgically removed from acromegalic patients, who did not receive medical treatment with somatostatin analogs before surgery $(n=8)$. The removed tissues were in part quickly frozen for subsequent molecular studies and in part placed in sterile medium for cell culture, after the exclusion of blood cell contamination, as previously described (Lania et al. 2004). Local ethical approval was obtained for the study.

\section{SST2 and SST5 mRNA and protein quantification}

To quantify SST2 and SST5 mRNA levels, total RNA was isolated from tumor tissues, reverse transcribed (primers and amplification conditions available on request) and evaluated by real-time reverse transcription-polymerase chain reaction (RT-PCR) based on TaqMan methodology, as previously reported (Luciani et al. 2005). Total proteins were extracted from the same tissues, homogenized with PBS and quantified using the BCA protein assay kit (Pierce, Rockford, IL, USA). Twenty micrograms of protein were resolved on
10\% SDS-PAGE gel and transferred onto nitrocellulose membrane. Polyclonal antibodies specific for SSTR2 and SSTR5 were obtained from PRIM Laboratories (Milan, Italy) and used according to the manufacturer indications. The visualization and reading of the resulting bands were analyzed, as previously described (Lania et al. 2004). Experiments were repeated at least twice. To detect the specificity of the reaction, the antiserum was preincubated with the peptide against which the antibody was raised. As control, preparations of CHO-K1 cells transfected with human SST5 were positive for SST5 and negative for SST2 at immunoblotting (Ballarè et al. 2001). The expression of glyceraldeyde-3-phosphatedeydrogenase (GAPDH) by a mouse monoclonal anti-GAPDH antibody (Ambion Ltd, Huntingdon, Cambridgeshire, UK) was used as an internal control for protein loading.

\section{SST analogs}

The following SST analogs were used: octreotide with a specificity (IC50, nM) of 0.56 for SST2 and 7 for SST5; BIM23120 with a specificity of 0.34 for SST2, and 213 for SST5 and BIM23206 with a specificity of 166 for SST2 and 2.4 for SST5 (Ren et al. 2003). The superselective analogs were kindly provided by Biomeasure Incorporated/IPSEN (Milford, MA, USA)

\section{Caspase-3 activity}

Caspase-3 enzymatic activity was measured using Apo-ONE Homogenous Caspase-3 Assay (Promega). Briefly, tumoral cells were seeded in 96-well plates (50 000 cells/well) and treated with or without octreotide, BIM23120, BIM23206 (at 0.1, 1, 10, and $100 \mathrm{nM}$ ) for $6 \mathrm{~h}$ at $37^{\circ} \mathrm{C}$, in Dulbecco's modified essential medium (DMEM, Sigma Chemical) supplemented with $10 \%$ FCS. The timing of treatment was determined on the basis of preliminary experiments carried out at different time intervals showing the maximal stimulation at $6 \mathrm{~h}$. Experiments were repeated at least twice and each determination was done in quintuple.

\section{Cleaved cytokeratin (CK) 18 determination}

Cleaved CK18 levels were measured using M30Apoptosense ELISA (Peviva-Alexis, Bromma, Sweden). Briefly, 100000 tumoral cells were seeded in sixwell plates and incubated in the presence or absence of either octreotide or BIM23120 or BIM23206 for $16 \mathrm{~h}$ at $37^{\circ} \mathrm{C}$ and cell extracts were used for the assay, as previously described (Luciani et al. 2005). Experiments were repeated at least twice and each determination was done in triplicate. 


\section{Terminal deoxynucleotidyl transferase-mediated dUTP nick end labeling (TUNEL) analysis}

Apoptosis was also evaluated by TUNEL analysis, using a commercially available detection kit (APODIRECT, Phoenix Flow Systems, Inc., San Diego, CA, USA), as previously described (Luciani et al. 2005). Briefly, cells obtained from two growth hormone(GH) secreting adenomas were seeded in coverslips and incubated in the presence or absence of somatostatin analogs $(10 \mathrm{nM})$ for $16 \mathrm{~h}$ at $37^{\circ} \mathrm{C}$. The cells were fixed in $1 \%$ paraformaldehyde in PBS, $\mathrm{pH} 7.4$, treated with $70 \%$ ice ethanol for $30 \mathrm{~min}$ at $-20{ }^{\circ} \mathrm{C}$, exposed for $60 \mathrm{~min}$ at $37^{\circ} \mathrm{C}$ to the DNA labeling solution and observed using a transmission fluorescence microscope (Leitz, Type 307-148002, Wetzlar, Germany) equipped with an E4 filter (Leica, Milan, Italy). Images were captured by a Canon digital camera using Remote Capture software (provided by Canon, Machida, Japan) and edited by Adobe photoshop version5.0 (Adobe Systems Inc.).

\section{Cyclin D1 and p27 expression}

After $24 \mathrm{~h}$ of serum starvation, tumoral cells were incubated with BIM23120 or BIM23206 (10 nM) for $8 \mathrm{~h}$ at $37^{\circ} \mathrm{C}$. The determination of cyclin D1 was performed after immunoprecipitation of cell lysates with specific monoclonal antibodies (Novocastra, Newcastle, UK) and western blotting, as previously reported (Corbetta et al. 2005). The determination of p27 was performed after immunoprecipitation of cell lysates with specific polyclonal antibody (Upstate Europe, Dundee, UK) according to manufacturer instructions. Experiments were repeated at least twice. The expression of GAPDH by a mouse monoclonal anti-GAPDH antibody (Ambion Ltd) was used as an internal control for protein loading.

\section{Real-time PCR for apoptosis-related genes}

For the evaluation of the expression of nine apoptosisrelated genes (p53, p63, p73, Bcl-2, Bax, BID, BIK, TNFSF8, and FADD), total RNA obtained from cultured cells from three tumors after short(30 $\mathrm{min})$ and long-term $(16 \mathrm{~h})$ incubation with or without octreotide or BIM23120, was isolated, reverse transcribed, and evaluated by real-time RT-PCR, as previously described (Nosotti et al. 2005). Briefly, for the quantification of the three internal controls and the nine apoptosis-related genes we used a ready-to-use assay (Assay-on-Demand Gene Expression Products) purchased from Applied Biosystems. It consists of a $20 \times$ mix of unlabeled PCR primers and TaqMan
MGB probe (6-FAM at $5^{\prime}$ end and a no fluorescent quencher at $3^{\prime}$ end). The assay identification numbers of selected genes were: Hs00153340_m1 (TP53), Hs00186613_m1 (TP73L, p63), Hs00232088_m1 (TP73), Hs00153350_m1 (Bcl-2), Hs00180269_m1 (Bax), Hs00609630_m1 (BID), Hs00609635_m1 (BIK), Hs00174286_m1 (TNFSF8), and Hs0053 8709_m1 (FADD).

\section{Materials}

Octreotide (SMS 201-995) was provided by Novartis Pharma. DMEM, sodium orthovanadate, fetal calf serum (FCS) and okadaic acid were obtained from Sigma Chemical.

\section{Statistical analysis}

Results are expressed as the mean \pm s.D. A paired or unpaired two-tailed Student's $t$-test was used to detect the significance between two series of data. $P<0.05$ was accepted as statistically significant.

\section{Results}

\section{SSTR2 and SSTR5 expression}

The tumors included in the study showed clearly detectable levels of SST2 and SST5 mRNA and proteins. In particular, no significant difference between SST2 and SST5 mRNA levels was observed (Fig. 1A), despite certain variability among the different tumors (Fig. 1A). Moreover, receptor proteins were detected by specific antisera directed against SST2 and SST5 in all tumors (Fig. 1B), without striking differences among the individual tumors and clear correlations with mRNA levels.

\section{Effect of selective SST agonists on apoptosis and cyclin D1 expression}

In cultured cells obtained from all tumors, octreotide induced a dose-dependent increase in caspase-3 activity, that was detected at concentrations higher than $0.1 \mathrm{nM}$ and maximal at $10 \mathrm{nM}(160 \pm 20 \%$ vs basal, $P<0.05$ ) (Fig. 2). The limited amount of tissue available did not allow an accurate evaluation of the concentrations giving the half-maximal effect (ED50) that, however, resulted within the $0.5-2 \mathrm{nM}$ range. The selective SST2 analog BIM23120 induced an increase in caspase- 3 activity comparable with that caused by octreotide $(185 \pm 45 \%$ vs basal, at $10 \mathrm{nM}, P<0.05)$ in term of efficacy and potency, while the selective SST5 analog BIM23206 was ineffective (Fig. 2). The effects 


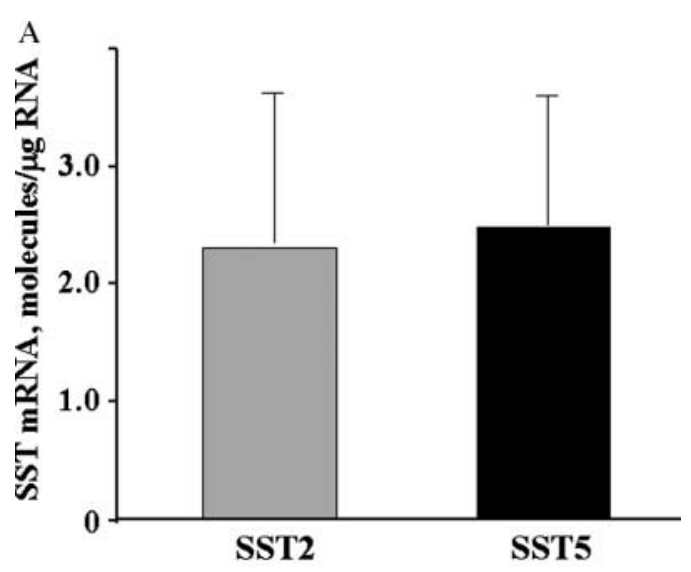

B

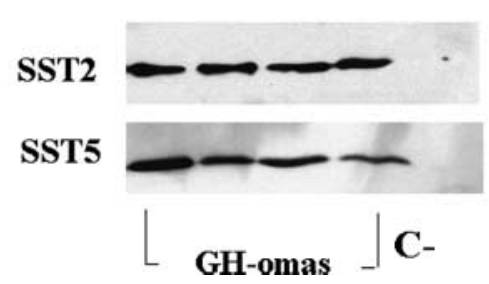

Figure 1 SST2 and SST5 expression in human somatotroph tumors. (A) SST2 and SST5 mRNA levels were detected in eight adenomatous tissue samples obtained by surgery, using real-time PCR technique. (B) Representative immunoblotting performed in four somatotroph tumors with antibodies raised against SST2 and SST5. C-, tumor tissue subjected to antiserum preincubated with $0.5 \mu \mathrm{g} / \mu \mathrm{l}$ peptide at $4{ }^{\circ} \mathrm{C}$ for $12 \mathrm{~h}$.

of octreotide and BIM23120 on caspase activity were similar to that induced by the aspecific proapoptotic agent okadaic acid $(205 \pm 25 \%$ vs basal, $P<0.05$; Fig. 2). Similar results were obtained by evaluating the effects of different somatostatin analogs on cleaved CK18 levels, a product of caspase- 3 activation (172 士 $25 \%$ vs basal, $P<0.05$; Fig. 3$)$. The stimulatory effects on both caspase-3 activity and CK18 levels were prevented by treating cultured cells with the phosphotyrosine phosphatase inhibitor orthovanadate $(25 \mu \mathrm{M}$; Figs 2 and 3). In these tumors, apoptosis was also assessed by TUNEL analysis, which is able to reveal the total number of apoptotic cells, independent of the activated pathways. As shown in Fig. 4, the number of apoptotic nuclei was markedly increased after BIM23120 exposure $(10 \mathrm{nM})$. No significant correlation between SST2 and SST5 mRNA and protein expression and caspase-3 activity and CK18 levels stimulation was observed.

Finally, in cultured cells obtained from three GH-secreting adenomas, both BIM23120 and BIM23206 $(10 \mathrm{nM})$ induced a reduction of about $50 \%$ in cyclin D1 expression (Fig. 5A) and an increase of about $200 \%$ in P27 expression (Fig. 5B).

\section{Effect of SST analogs on apoptosis-related genes}

Incubation of tumoral cells from three somatotroph tumors with octreotide $(10 \mathrm{nM})$ and BIM23120 $(10 \mathrm{nM})$ for 3 or $16 \mathrm{~h}$ did not induce any significant changes in p53, p63, p73, Bcl-2, Bax, BID, BIK, TNFSF8, and FADD mRNA levels as demonstrated by real-time quantitative RT-PCR (data not shown).

\section{Discussion}

This study confirmed that octreotide was able to induce apoptosis in human somatotroph tumor cells and provided novel evidence for the selective involvement of SST2 receptor in this process. Previous studies indicated that somatostatin and its analogs exert direct antiproliferative effects with cytostatic (growth arrest) and cytotoxic (apoptosis) consequences. The cytostatic effects of somatostatin have been documented in multiple cell types, including GH3 and AtT20 pituitary tumor cell lines (Cheung \& Boyages 1995, Srikant 1995). Studies performed in cells stably expressing the cDNA encoding the human SST2 and SST5 sequences strongly supported the involvement of these receptor subtypes in the cytostatic action of somatostatin. In particular, in these systems somatostatin caused cell cycle arrest in $\mathrm{G} 1$, due to upregulation of $\mathrm{Rb}$ and cyclin-dependent kinase inhibitors, such as p27, p21, and p16 (Pages et al. 1999, Sharma et al. 1999). The cytostatic action of somatostatin was confirmed by the present study that showed a significant increase in cyclin-dependent kinase inhibitors p27 expression together with a significant reduction of cyclin D1, a cell cycle progression protein, by both SST2 and SST5 selective analogs in somatotroph tumors.

Until recently, SST3 was considered the only receptor subtype able to trigger apoptotic signals (Sharma et al. 1996). Subsequently, it has been demonstrated that also SST2 may initiate apoptotic pathways in cell lines expressing human SST2, including AtT20 pituitary cells (Srikant 1995, Gruszka et al. 2001). Consistent with recent data from our laboratory (Luciani et al. 2005), octreotide was able to increase the enzymatic activity of caspase3 , a major protease mediator of the extrinsic and intrinsic apoptotic pathway, in all somatotroph tumors investigated. Moreover, the present study clearly identified SST2 as the receptor subtype involved in the proapoptotic action triggered by octreotide in these tumors. In fact, although the superselective analog of SST3 was not available for a direct receptor activation, the involvement of SST3 in 

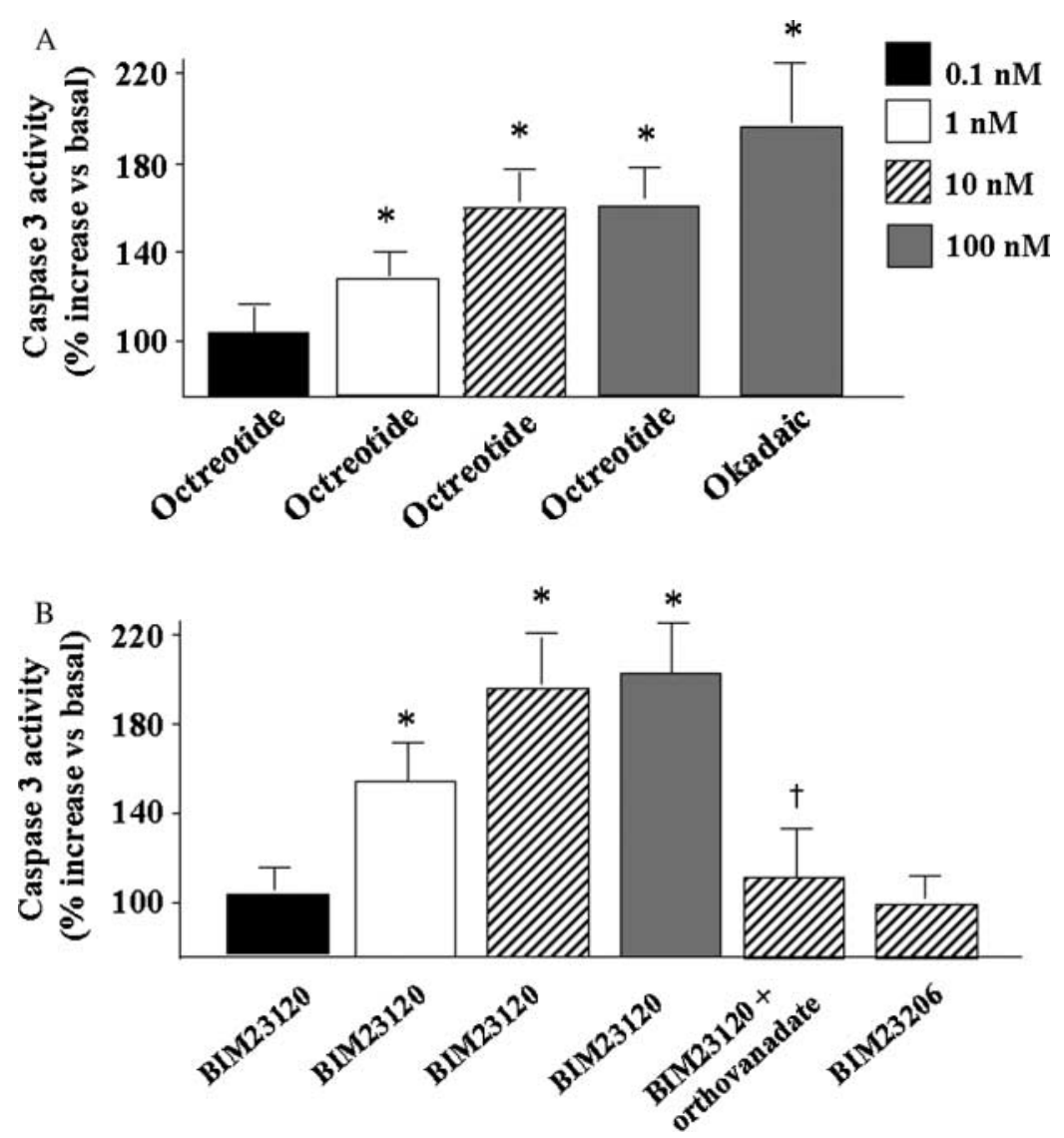

Figure 2 Effects of somatostatin analogs on apoptosis in human somatotroph tumors: (A) octreotide induced a dose-dependent increase in caspase-3 activity, that was maximal at $10 \mathrm{nM}$ and similar to the increase induced by the aspecific proapoptotic agent okadaic acid (100 nM). The selective SST2 analog BIM23120 caused a dose-dependent increase in caspase-3 activity that was prevented by the phosphatase inhibitor orthovanadate $(25 \mu \mathrm{M})$. (B) Conversely, the selective SST5 analog BIM23206 did not significantly affect apoptosis in any $\mathrm{GH}$-omas. Experiments were repeated at least twice and each determination was done in quintuple. Data represent the percent increase (mean \pm s.D.) of both caspase-3 activity over basal values, arbitrarily defined as $100 \%$, in eight GH-omas ${ }^{*} P<0.05$ vs basal; $\uparrow P<0.05$ vs BIM23120.

octreotide-induced apoptosis seems unlikely, taking into account the low affinity of octreotide for this receptor together with the low expression of SST3 found in somatotroph tumors, in comparison with SST2 and SST5 (Ren et al. 2003, Luciani et al. 2005). Moreover, octreotide and BIM23120 concentrations effective in activating the apoptotic process resulted to be in the dose range reported to inhibit in vitro $\mathrm{GH}$ release (Ren et al. 2003).

The mechanisms involved in growth arrest and apoptosis induced by somatostatin are only partially elucidated. However, accumulating evidence indicate that cell cycle arrest is largely mediated by SST2induced activation of SHP-1 and SHP-2, two members of the Src homology 2 (SH2) containing tyrosine phosphatase family (Pages et al. 1999, Ferjoux et al. 2003). In addition to inducing cell arrest, tyrosine

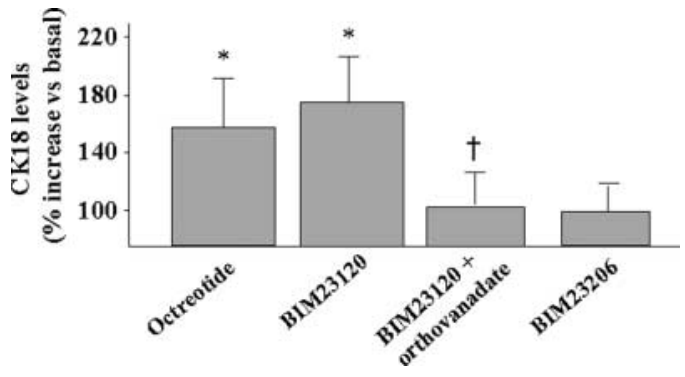

Figure 3 Effect of somatostatin analogs on cleaved CK18, a product of caspase-3 activation. Both octreotide $(10 \mathrm{nM})$ and the selective SST2 agonist BIM $23120(10 \mathrm{nM})$ induced a significant increase in cleaved CK18 levels that was prevented by the phosphatase inhibitor orthovanadate $(25 \mu \mathrm{M})$. No effect was induced by the selective SST5 agonist (BIM23206, $10 \mathrm{nM}$ ). Data represent the percent increase (mean \pm s.D.) of cleaved CK18 levels over basal values, arbitrarily defined as $100 \%$, in eight $\mathrm{GH}$-omas ${ }^{*} P<0.05$ vs basal; $\uparrow P<0.05$ vs BIM23120. 

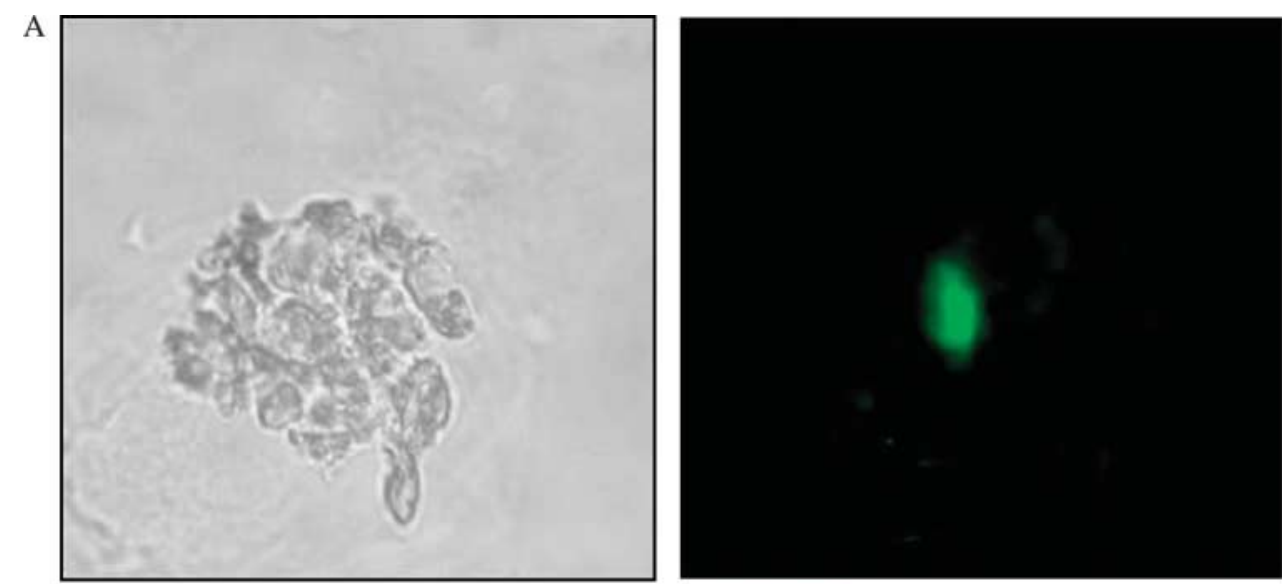

B
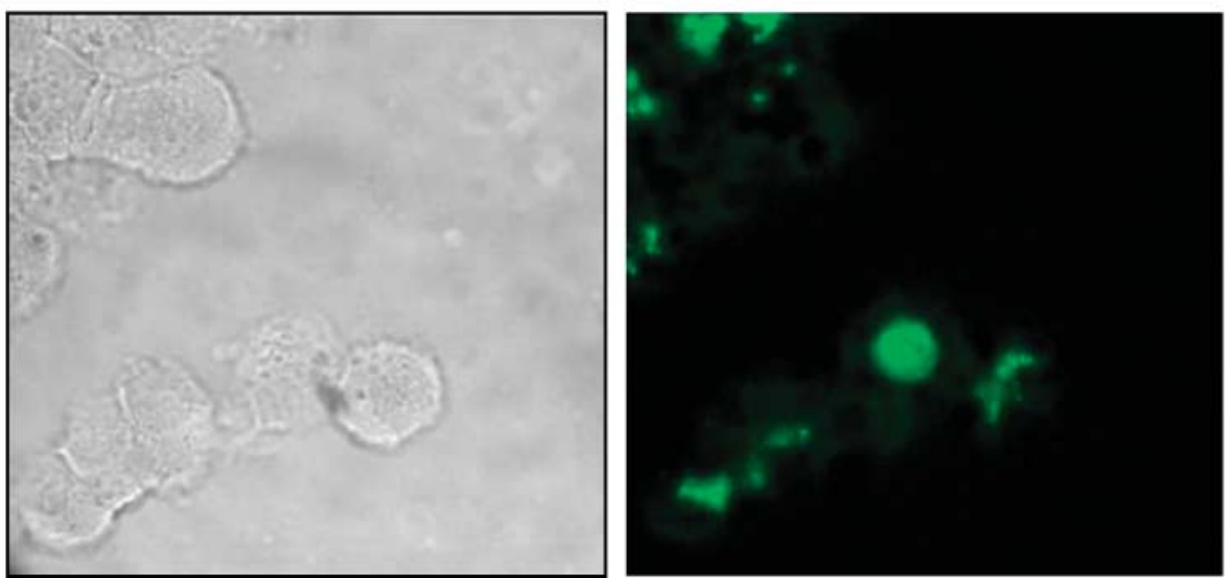

Figure 4 Determination of apoptotic nuclei by TUNEL analysis in cells from somatotroph tumors both in basal conditions (A) and upon BIM23120 treatment (B). Green fluorescence (right) and bright images (left) from the same field are shown. A few apoptotic nuclei were observed in basal conditions (A), whereas nuclear fluorescence markedly increased after BIM23120 exposure, as shown in B. Magnification $100 \times$.

phosphatases have been demonstrated to represent essential components of somatostatin-mediated cytotoxic signaling that causes intracellular acidification and apoptosis in MCF-7 human breast cancer cells (Thangaraju et al. 1999). Consistent with the view that SST2 signals by recruiting and activating phosphotyrosine phosphatases, initiation of apoptotic pathway by octreotide and BIM23120 in tumoral somatotroph cells required the activation of these enzymes.

We also investigated the induction of apoptosisrelated genes by SST2 activation in human somatotroph tumor cells. On the basis of intrinsic cell death pathway previously reported for SST3 that involved p53 and Bax induction (Sharma et al. 1996), the expression of genes belonging to p53 family (p53, p63, and p73) and to two subfamilies of proapoptotic Bcl-2 family (Bax and BH3-only) was investigated. In addition, extrinsic apoptotic pathway was partially studied through FADD and TNFSF8 expression. Incubation with octreotide and BIM23120, both after short and long-term, did not induce significant modifications on gene expression. Accordingly, it has been reported that SST2 may induce death of HL-60 cells, a cell line with a null p53 phenotype due to p53 gene deletion (Teijeiro et al. 2002). Moreover, as observed HL-60 cells (Teijeiro et al. 2002), SST2 activation did not modify the expression of other candidate genes, such as $\mathrm{p} 73$, that can induce apoptosis even in the absence of p53 (Zhu et al. 2001). In this respect, it has been proposed that cytosolic accumulation of p53 may activate Bax and trigger mitochondrial membrane permeabilization and apoptosis by a transcription-independent mechanism (Chipuk et al. 2004). Further studied are needed to ascertain the cell death pathways underlying the apoptotic effect induced by SST2 analog in somatotroph tumor cells, 

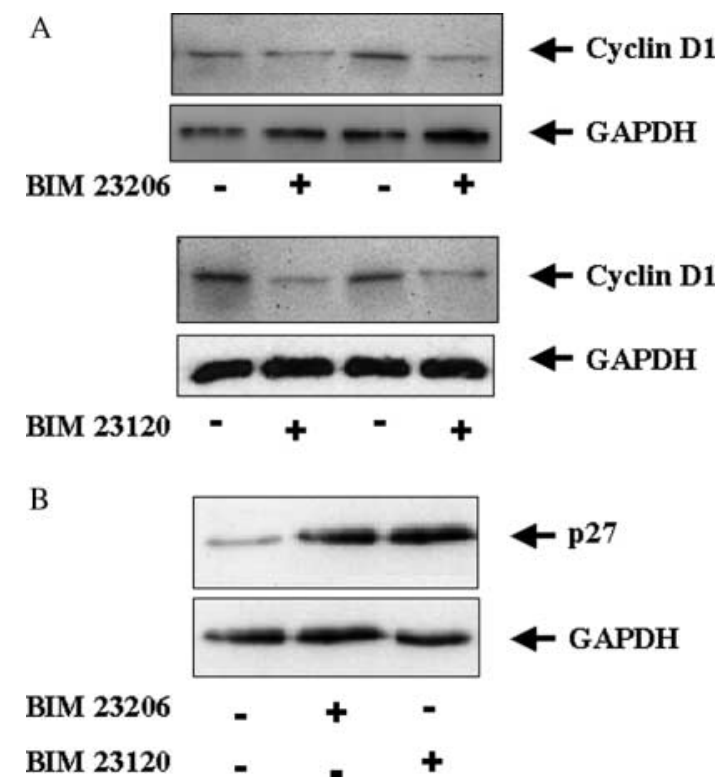

Figure 5 Representative immunoblotting showing the effect of SST5 and SST2 activation on cyclin D1 expression in cultured cells obtained from three GH-omas. Both SST2 (BIM23120) and SST5 (BIM23206) selective analogs reduced cyclin D1 (A) and increased expression of cyclin-dependent kinase inhibitors p27 (B). GAPDH protein expression has been used as an internal control.

that resulted to be different from those previously reported for SST3 (Sharma et al. 1999).

Apoptosis is a physiological process of programmed cell death triggered by a number of stimuli, including hormones, DNA damage, and anticancer drugs. Moreover, apoptosis in response to antineoplastic agents correlates with tumor shrinkage. The presence of morphological apoptotic features, such as cell shrinkage, nuclear condensation, membrane blebbing and DNA fragmentation, in surgical specimens obtained from acromegalic patients chronically treated with long acting somatostatin analogs has been reported by some authors and negated by others (Losa et al. 2001, Wasko et al. 2003). Despite these discrepant data, it is tempting to speculate that the in vitro cytotoxic effects induced by SST2 activation in somatotroph tumor cells may be involved in the tumor shrinkage observed in a consistent proportion of acromegalic patients treated with somatostatin analogs (Bevan 2005, Freda et al. 2005). Admittedly, large series of tumors, including those resulted to be resistant to octreotide in vivo and removed after an appropriate washout period, would be required in order to assess the possible correlation between in vitro proapoptotic action of sst 2 analog and in vivo antitumoral action of octreotide.

In conclusion, the present study showed that octreotide-induced apoptosis in human somatotroph tumor cells by activating SST2. This effect, together with the cytostatic action exerted by both SST2 and SST5 analogs, might account for the antineoplastic effect of long-acting somatostatin analogs in acromegaly.

\section{Acknowledgements}

We thank Dr Culler for providing us with BIM23120 and BIM23206. The present study was partially supported by research grants from Ministero dell'Università e Ricerca Scientifica (MURST, Rome) and from Ospedale Maggiore IRCCS (Milan) and Associazione Italiana per la Ricerca sul Cancro AIRC (Milan). The authors declare that there is no conflict of interest that would prejudice the impartiality of this scientific work.

\section{References}

Ballare E, Persani L, Lania AG, Filopanti M, Giammona E, Corbetta S, Mantovani S, Arosio M, Beck-Peccoz P, Faglia G et al. 2001 Mutation of somatostatin receptor type 5 in an acromegalic patient resistant to somatostatin analog treatment. Journal of Clinical Endocrinology and Metabolism 86 3809-3814.

Benali N, Ferjoux G, Puente E, Buscail L \& Susini C 2000 Somatostatin receptors. Digestion 62 27-32.

Bevan JS 2005 Clinical review: the antitumoral effects of somatostatin analog therapy in acromegaly. Journal of Clinical Endocrinology and Metabolism 90 1563-1856.

Cheung NW \& Boyages SC 1995 Somatostatin-14 and its analog octreotide exerts cytostatic effects on $\mathrm{GH} 3$ rat pituitari tumor cell proliferation via transient G0/G1 cell cycle block. Endocrinology 136 4174-4181.

Chipuk JE, Kuwana T, Bouchier-Hayes L, Droin NM, Newmeyer DD, Schuler M \& Green DR 2004 Direct activation of Bax by p53 mediates mitochondrial membrane permeabilization and apoptosis. Science $\mathbf{3 0 3}$ 1010-1014.

Corbetta S, Vicentini L, Ferrero S, Lania A, Mantovani G, Cordella D, Beck-Peccoz P \& Spada A 2005 Activity and function of the nuclear factor kappaB pathway in human parathyroid tumors. Endocrine-Related Cancer 12 929-937.

Ferjoux G, Lopez F, Esteve JP, Ferrand A, Vivier E, Vely F, Saint-Laurent N, Pradayrol L, Buscail L \& Susini C 2003 Critical role of Src and SHP-2 in sst2 somatostatin receptor-mediated activation of SHP-1 and inhibition of cell proliferation. Molecular Biology of the Cell $\mathbf{1 4}$ 3911-3928.

Freda PU, Katznelson L, van der Lely AJ, Reyes CM, Zhao S \& Rabinowitz D 2005 Long-acting somatostatin analog therapy of acromegaly: a meta-analysis. Journal of Clinical Endocrinology and Metabolism 90 4465-4473. 
Gruszka A, Pawlikowski M \& Kunert-Radek J 2001 Anti-tumoral action of octreotide and bromocriptine on the experimental rat prolactinoma: anti-proliferative and pro-apoptotic effects. Neuroendocrinology Letters 22 343-348.

Hofland LJ, van Hagen PM \& Lamberts SW 1999 Functional role of somatostatin receptors in neuroendocrine and immune cells. Annals of Medicine 13 23-27.

Lamberts SW, de Herder WW \& Hofland LJ 2002 Somatostatin analogs in the diagnosis and treatment of cancer. Trends in Endocrinology and Metabolism 13 451-457.

Lania AG, Mantovani G, Ferrero S, Pellegrini C, Bondioni S, Peverelli E, Braidotti P, Locatelli M, Zavanone ML, Ferrante E et al. 2004 Proliferation of transformed somatotroph cells related to low or absent expression of protein kinase A regulatory subunit $1 \mathrm{~A}$ protein. Cancer Research 64 9138-9193.

Losa M, Ciccarelli E, Mortini P, Barzaghi R, Gaia D, Faccani G, Papotti M, Mangili F, Terreni MR, Camanni F et al. 2001 Effects of octreotide treatment on the proliferation and apoptotic index of GH-secreting pituitary adenomas. Journal of Clinical Endocrinology and Metabolism 86 5194-5200.

Luciani P, Gelmini S, Ferrante E, Lania A, Benvenuti S, Baglioni S, Mantovani G, Cellai I, Ammannati F, Spada A et al. 2005 Expression of the anti-apoptotic gene seladin-1 and octeotide-induced apoptosis in GH-secreting and in non-functioning pituitary adenomas. Journal of Clinical Endocrinology and Metabolism 90 6156-6161.

Nosotti M, Falleni M, Palleschi A, Pellegrini C, Alessi F, Bosari S \& Santambrogio L 2005 Quantitative real-time polymerase chain reaction detection of lymph node lung cancer micrometastasis using carcinoembryonic antigen marker. Chest 128 1539-1544.

Oberg K, Kvols L, Caplin M, Delle Fave G, de Herder W, Rindi G, Ruszniewski P, Woltering EA \& Wiedenmann B 2004 Consensus report on the use of somatostatin analogs for the management of neuroendocrine tumors of the gastroenteropancreatic system. Annals of Oncology 15 966-973.

Pages P, Benali N, Saint-Laurent N, Esteve JP, Schally AV, Tkaczuk J, Vaysse N, Susini C \& Buscail L 1999 SST2 somatostatin receptor mediates cell cycle arrest and induction of p27(Kip1). Evidence for the role of SHP-1. Journal of Biological Chemistry 274 15186-15193.

Patel YC 1999 Somatostatin and its receptor family. Frontiers in Neuroendocrinology 20 157-198.

Ren SG, Taylor J, Dong J, Yu R, Culler MD \& Melmed S 2003 Functional association of somatostatin receptor subtypes 2 and 5 in inhibiting human growth hormone secretion. Journal of Clinical Endocrinology and Metabolism 88 4239-4245.

Sharma K, Patel YC \& Srikant CB 1996 Subtype-selective induction of wild-type p53 and apoptosis, but not cell cycle arrest, by human somatostatin receptor 3. Molecular Endocrinology 10 1688-1696.

Sharma K, Patel YC \& Srikant CB 1999 C-terminal region of human somatostatin receptor 5 is required for induction of $\mathrm{Rb}$ and G1 cell cycle arrest. Molecular Endocrinology 13 82-90.

Srikant CB 1995 Cell cycle dependent induction of apoptosis by somatostatin analog SMS 201-995 in AtT-20 mouse pituitary cells. Biochemical and Biophysical Research Communications 209 400-406.

Teijeiro R, Rios R, Costoya JA, Castro R, Bello JL, Devesa J \& Arce VM 2002 Activation of human somatostatin receptor 2 promotes apoptosis through a mechanism that is independent from induction of p53. Cellular Physiology and Biochemistry 12 31-38.

Thangaraju M, Sharma K, Leber B, Andrews DW, Shen SH \& Srikant CB 1999 Regulation of acidification and apoptosis by SHP-1 and Bcl-2. Journal of Biological Chemistry $27429549-29557$.

Wasko R, Jankowska A, Kotwicka M, Liebert W, Sowinski J \& Warchol JB 2003 Effects of treatment with somatostatin analogues on the occurrence of apoptosis in somatotropinomas. Neuroendocrinology Letters 24 334-338.

Weckbecker G, Lewis I, Albert R, Schmid HA, Hoyer D \& Bruns C 2003 Opportunities in somatostatin research: biological, chemical and therapeutic aspects. Nature Review Drug Discovery 2 999-1017.

Zhu J, Nozell S, Wang J, Jiang J, Zhou W \& Chen X 2001 p73 cooperates with DNA damage agents to induce apoptosis in MCF7 cells in a p53-dependent manner. Oncogene 20 450-457. 